\title{
Poder disciplinario y derecho en Michel Foucault. Notas críticas
}

\author{
Disciplinary Power and Law in Michel Foucault. Critical Notes \\ Poder disciplinar e direito em Michel Foucault. Notas críticas
}

\author{
MAURO BENENTE* \\ Universidad de Buenos Aires
}

FECHA DE RECEPCIÓN: 22 DE JULIO DE 2013 • FECHA DE ACEPTACIÓN: 8 DE MAYO DE 2014

Doi: dx.doi.org/10.12804/esj 16.02.2014.07

Para citar este artículo: Benente, M. (2014). Poder disciplinario y derecho en Michel Foucault. Notas críticas. Estudios SocioJurídicos, 16(2), 213-242. Doi: dx.doi.org/10.12804/esj16.02.2014.07

\section{RESUMEN}

Uno de los aportes más interesantes de las reflexiones de Michel Foucault durante la década de 1970 ha sido dar cuenta de un funcionamiento productivo de las relaciones de poder. En el presente trabajo, intentaré indicar que, a pesar de que Foucault postuló un funcionamiento productivo de las relaciones de poder, mantuvo una mirada netamente represiva sobre la ley. Así mismo, trataré de mostrar que esta reducción de la ley a mera prohibición le impidió dar cuenta del papel que ella cumple en las sociedades disciplinarias.

Palabras clave: poder, disciplina, derecho, represión, prohibición.

* Abogado, Universidad de Buenos Aires, y doctorando en Derecho de la misma Universidad. Profesor de Teoría del Estado en las facultades de Derecho de la Universidad de Buenos Aires y de la Universidad de Palermo, y de Análisis Jurisprudencial de la Corte Suprema en la UNPAZ; profesor a cargo del curso "Michel Foucault, el derecho y el poder" en la Facultad de Derecho de la Universidad de Buenos Aires; investigador del Instituto de Investigaciones Jurídicas y Sociales A. L. Gioja y director del proyecto de investigación DECyT "El derecho y el poder en y desde Michel Foucault". Becario doctoral del Conicet. Correo electrónico: maurobenente@yahoo.com 


\section{ABSTRACT}

One of the most interesting contributions of Michel Foucault's reflections during the 1970s has been to account for productive operation of power relations. In this paper I try to show that although Foucault has postulated a productive functioning of power relations, he maintained a purely repressive look on the law. Also, I try to show that the reduction of the law to a mere prohibition prevented him from giving account of the role of law in disciplinary societies.

Key words: power, discipline, law, repression, prohibition.

\section{RESUMO}

Um dos aportes mais interessantes das reflexões de Michel Foucault durante a década de 1970 tem sido dar conta de um funcionamento produtivo das relações de poder. No presente trabalho, tentarei indicar que apesar de que Foucault postulou um funcionamento produtivo das relações de poder, manteve uma mirada netamente repressiva sobre a lei. Igualmente, tentarei mostrar que esta redução da lei a mera proibição, lhe impediu dar conta do papel que ela cumpre nas sociedades disciplinarias.

Palavras-chave: Poder, disciplina, direito, repressão, proibição. 


\section{Introducción}

Gran parte del discurso jurídico suele presentarse como autónomo de los procesos sociales, económicos, culturales e históricos. Por momentos el derecho se erige como un objeto de estudio completamente autónomo o, cuanto mucho, es vinculado con el discurso moral. Sin embargo, desde tradiciones críticas, de insular presencia en el discurso jurídico predominante, el derecho sí se presenta íntimamente relacionado con las problemáticas políticas, económicas y de poder.

Por su lado, dentro de la temática del poder, los trabajos de Michel Foucault han aportado una notable frescura y en obras como Historia de la sexualidad I. La voluntad de saber, así como en "Hay que defender la sociedad", es posible hallar una importante e interesante sistematización sobre la necesidad de desprenderse de la teoría jurídico-politica de la soberanía o de la representación jurídica del poder y avanzar hacia una nueva analítica del poder. No obstante, la urgencia por abandonar este modo de representación del poder, aunque sin estar etiquetada de este modo, puede rastrearse en cursos e intervenciones pretéritas. Es así que uno de los puntos de rechazo a esta representación jurídica es la idea según la cual el poder se localiza exclusivamente en el Estado, hipótesis que Foucault combatió desde los tempranos trabajos de la década de 1970. Sin embargo, en estos textos de inicios del decenio, y a diferencia de lo que sucederá a partir del curso dedicado a "Los anormales", todavía mantenía una idea según la cual el poder reprime, algo que será rechazado enfáticamente a partir del citado curso.

En "Los anormales", en Vigilar y castigar y en Historia de la sexualidad I, Foucault criticó la noción de represión como grilla de inteligibilidad de las relaciones de poder, e intentó sugerir que con la emergencia de las sociedades disciplinarias las relaciones eran eminentemente productivas. De todos modos, en esos mismos trabajos, en los cuales expresamente apelaba a la necesidad de concebir al poder en términos productivos, mantuvo a la ley como una herramienta exclusivamente prohibitiva, eminentemente negativa. Así mismo, en esos textos, ha trazado una notable distinción entre el funcionamiento de las disciplinas y el funcionamiento de las leyes. En este artículo, a partir de los propios ejemplos históricos empleados por Foucault, me interesará problematizar tanto esa reducción de la ley a mera represión cuanto esta separación entre disciplinas y leyes. A partir de esta problema- 
tización, entiendo que es posible articular el derecho con el funcionamiento de las relaciones de poder, algo que Foucault no logró visualizar con nitidez, y que el discurso jurídico predominante no está dispuesto a aceptar.

\section{Al principio fue represión y prohibición}

Luego de las críticas recibidas a partir de la publicación de Las palabras y las cosas, en sus premisas metodológicas para analizar la producción del discurso, Foucault comenzó a incluir las prácticas no discursivas. Tal como aparece en "Respuesta a una cuestión" y en La arqueología del saber, en su producción, los discursos responden a reglas impuestas por las prácticas discursivas, pero también por prácticas no discursivas (Foucault, 2001 ñ, pp. 705-708). Todavía en relación con las reglas de formación de los discursos, en El orden del discurso, Foucault deja de hablar de prácticas no discursivas para referirse al poder.

Si se toma una fotografía de El orden del discurso, y máxime en comparación con trabajos anteriores, entiendo que es fácil advertir que se presenta un mayor énfasis en las prácticas no discursivas que en las prácticas discursivas. De hecho, de los tres mecanismos de control sobre los discursos, esto es, los controles internos, los externos y los relativos al sujeto que enuncia, los últimos dos están basados más en prácticas no discursivas que en prácticas discursivas. De todos modos, más allá de las particularidades de los controles externos, internos y relativos al sujeto que enuncia, es importante destacar que "la importancia de todo ese conjunto de restricciones que operan en el ordenamiento de los discursos radica en que permiten identificar una variable fundamental: el poder es una fuerza externa e interna que delimita las prácticas discursivas" (Castro, 2004, p. 86). No obstante, a pesar de que la temática del poder parece sobrevolar los tres mecanismos de control, y que, al momento de tematizar los controles sobre el sujeto que enuncia, Foucault vincula expresamente la educación con la política, es en los mecanismos de exclusión externos donde creo que se encuentra más presente. En algún sentido, podría decirse que "[d]etrás de estas exclusiones, expresa o tácitamente, se nos habla del poder" (Godoy, 1990, p. 110).

Según entiendo, todavía en relación con la temática de los discursos, se advierte una mirada negativa sobre el funcionamiento de las relaciones 
de poder. De todos modos, en los primeros años del decenio de 1970, Foucault comenzó a referirse de forma negativa al poder ya sin referencias al asunto de los discursos, algo que también había realizado en su tesis doctoral: en una entrevista que le realizaron en 1976, admitió que en Historia de la locura en la época clásica, todavía suponía una idea de poder asociado con un mecanismo de represión (Foucault, 2001e, p. 148). De hecho, sin necesidad de realizar un estudio minucioso de todo el trabajo, en el prólogo original de la obra, y contrariamente a lo que finalmente fue el proyecto de Historia de la sexualidad I. La voluntad de saber -en donde se esforzó por mostrar las deficiencias de la hipótesis represiva sobre la sexualidad-, Foucault afirmaba que era necesario realizar la historia "de las prohibiciones sexuales: en nuestra cultura misma, hablar de las formas continuamente móviles y obstinadas de la represión" (Foucault, 2001 m, p. 190). En el mismo orden de ideas, en "La locura, la ausencia de obra" - escrito en 1964 y luego incluido como apéndice en la segunda edición de Historia de la locura en 1972-, asoció nuevamente el poder a la represión, puesto que se refirió a la "represión de la locura como palabra prohibida" (Foucault, 2001g, p. 445).

De todas maneras, no hay que remontarse hasta su tesis doctoral para encontrar señales de una mirada del poder como mera represión. Es así que, en consonancia con aquel prólogo en "Locura, literatura, sociedad", una entrevista publicada en diciembre de 1970, todavía se refería a la represión sobre la sexualidad. Así se lee que "[lla sociedad en la que vivimos limita considerablemente la libertad sexual, directa o indirectamente" (Foucault, 2001 g, p. 986). Es cierto que en Europa desde 1726 ya no se ejecutaba a los homosexuales, pero el tabú de la homosexualidad todavía se encontraba muy presente. Así mismo, indicaba que "[lla sexualidad es reprimida en particular desde el siglo XIX, más de lo que ha sido reprimida en cualquier otro siglo. Hay que hablar de la sexualidad y hay que practicarla sólo según las modalidades definidas por la sociedad burguesa" (Foucault, 2001 g, p. 990).

Por su lado, en noviembre de 1971, en la Escuela Superior de Tecnología de Eindhoven, Foucault mantuvo con Noam Chomsky un debate grabado para la televisión holandesa, titulado "Naturaleza humana: justicia versus poder". ${ }^{1}$ La conversación giró alrededor de varios puntos, uno de

1 Bajo el título de "Human nature: justice versus power", el debate fue publicado por primera 
los cuales hizo foco en cuestiones políticas, marco en el cual se deslizaron algunas reflexiones sobre la temática del poder. Se le consultó a Foucault si se podían calificar como democráticas a las sociedades contemporáneas y no solamente afirmó que no podía aplicarse tal caracterización, sino que además, y aquí se advierte una mirada sobre el poder en términos más represivos que productivos, postuló que "está totalmente claro que vivimos bajo un régimen de dictadura de clase, de poder de clase que se impone por la violencia, incluso cuando los instrumentos de esta violencia son institucionales y constitucionales" (Foucault, 2001c, p. 1363). Luego, con un aire de familia a sus trabajos posteriores, aclaraba que este poder se ejercía no solamente en el Estado, sino en otras instituciones, como la familia, las entidades médicas, la universidad y el sistema de enseñanza (Foucault, 2001c, p. 1364).

Es en este orden de ideas, y en comparación a lo que se leerá en trabajos posteriores, es notable que, en estos primeros años de la década de 1970, Foucault analizaba la prisión en términos represivos. En una entrevista que le realizaron en marzo de 1971, sostenía que la cárcel tenía dos caras, una más visible, la de su justificación por la existencia de la delincuencia. Pero también tenía "[l]a parte oculta, la más importante, la más temible: la prisión es un instrumento de represión social" (Foucault, 2001d, p. 1047). ${ }^{2}$ Por su lado, en una entrevista publicada en julio de 1971, cuando se le preguntó por la misión del Grupo de Información sobre las Prisiones, indicó que el objetivo era darles la palabra a los detenidos y que de ningún modo "se trata de proponer una prisión ideal. Creo que por definición la prisión es un instrumento de represión" (Foucault, 2001f, p. 1072). Por otro lado, algunos meses después, en "Sobre la justicia popular", una discusión con militantes del maoísmo publicada en febrero de 1972, Foucault se quejaba por la inexistencia de estudios sobre la justicia penal, la cual no dudaba en caracterizar en términos represivos: "[S]e realiza la historia del derecho, la historia de la economía, pero la historia de la justicia, de la práctica judicial, de lo que ha sido efectivamente el sistema penal, de lo que han sido los sistemas de represión, sobre eso, raramente se habla" (Foucault, 2001 o, p. 1218).

vez en Londres en 1974 en una compilación a cargo de Fons Elders -quien había coordinado el debate televisivo titulado Reflexive water: the basic concerns of mankind-.

2 En la misma entrevista, cuando se le preguntó qué era lo más insoportable de la prisión, respondió que era la represión sexual que funciona en ella (Foucault, 2001d, p. 1048). 
Continuando con la temática de la prisión, en una entrevista publicada el 2 de junio de 1973, se le preguntó si era deseable reformar el sistema penitenciario o, más bien, era menester romper todos los esquemas tradicionales sobre el derecho penal. Foucault contestó que la práctica del encierro bajo vigilancia en vistas a que los individuos sean reformados había fracasado completamente, pero, de todos modos, "[e]ste sistema forma parte de un sistema más vasto y complejo que es, si usted quiere, el sistema punitivo: los niños son castigados, los estudiantes son castigados, los obreros son castigados, los soldados son castigados. En síntesis, se castiga durante toda su vida" (Foucault, 2001 n, pp. 1297-1298).

Es así que "Iplara que los individuos sean una fuerza de trabajo disponible para el aparato de producción, es necesario un sistema de coacciones, coerción y castigo, un sistema penal y un sistema penitenciario" (Foucault, 2001 n, p. 1298). Se le consultó si la existencia de este sistema punitivo podía ser probado históricamente, y afirmó que "[h]ubo desde inicios del siglo XIX, toda una serie de instituciones que han funcionado de acuerdo con el mismo modelo, que obedecían las mismas reglas, y cuya primera descripción, casi delirante, se encuentra en el célebre Panopticon de Bentham" (Foucault, 2001 n, p. 1298). Se trataba de instituciones en las cuales se fijaba a los individuos al aparato de producción, a un oficio, a un aparato escolar, a aparatos punitivos, correctivos o sanitarios. Los individuos se encontraban

[...] fijados a este aparato, compelidos a obedecer un determinado número de reglas de existencia que enmarcaban toda su vida -y aquí bajo la vigilancia de un cierto número de personas, de cuadros (capataces, enfermeros, guardiacárceles) que disponían de medios de castigos que consistían en multas en las fábricas, correcciones físicas o morales en las escuelas y en los asilos y, en la prisión, en un cierto número de penas violentas y esencialmente físicas- (Foucault, 2001 n, p. 1298).

Las instituciones que aquí presenta Foucault, incluso el propio panopticon, serán retomadas en varias oportunidades, pero aquí la mirada sobre el poder se limita a su dimensión punitiva, coactiva, represiva.

Esta visualización que otorgaba a las instituciones un funcionamiento eminentemente represivo puede leerse en otras entrevistas y breves trabajos, y generalmente la institución marcada, junto con la cárcel, es el hospital 
psiquiátrico -o la psiquiatría como disciplina-. De este modo, en "Más allá del bien y del mal", una entrevista publicada en noviembre de 1971, afirmaba que "[...] el rol represivo del asilo psiquiátrico es conocido: en él se encierra a la gente y se les entrega a una terapéutica -química o psicopatológica- sobre la cual no tienen ninguna decisión, o a una no terapéutica que es la camisa de fuerza" (Foucault, 20011, p. 1100).

En el mismo orden de ideas, en "A modo de conclusión" - una breve nota aparecida en Le Nouvel Observateur en marzo de 1973 a propósito de un artículo escrito por el psicólogo estadounidense David L. Rosenhan y titulado "Yo me hago pasar por loco"-, indicaba que hacer de un sentimiento que se modifica o de un momento de cólera un diagnóstico de esquizofrenia no implicaba otra cosa que "establecer una relación de poder que permite aislar, encerrar, suspender los derechos e interrumpir la vida" (Foucault, 2001i, p. 1286). En la misma línea, en el también muy breve artículo "El mundo es un gran asilo", aparecido en junio de 1973, Foucault sostenía que en el siglo XIX caía la monarquía como sistema de gobierno y con ello el poder ya no se heredaba, sino que comenzaba a ejercerse con la intervención de un tipo de saber gubernamental, y es por ello por lo que el poder empezaba a vincularse con el saber. De todos modos, en la actualidad, el mundo estaba avanzando hacia un modelo hospitalario, puesto que el gobierno "adquiere una función terapéutica. La función de los dirigentes es de adaptar los individuos a los procesos de desarrollo, según una variable de ortopedia social" (Foucault, 2001i, p. 1301). Ahora bien, bajo este prisma de reducir el poder a la represión, Foucault no deja de recordarnos que la "terapia médica es una forma de represión" (Foucault, 2001i, p. 1286).

Es interesante tener en cuenta que en estos primeros trabajos, y a diferencia de lo que ocurrirá en desarrollos posteriores, Foucault no solamente concibe a la prisión y al hospital psiquiátrico como instituciones que funcionan en términos represivos, sino que también parece indicar que el individuo normal se logra a partir de la represión. Es así que en "Más allá del bien y del mal", una entrevista que salió a la luz en noviembre de 1971, Foucault sostenía que "Illa lucha antidroga es un pretexto para reforzar la represión social: cuadrículas policiales, pero también la exaltación del hombre normal, racional, consciente y adaptado" (Foucault, 20011, p. 1098). Así mismo, bajo este prisma de dar con una constitución de la normalidad a 
partir de la represión, en una conversación mantenida con Gilles Deleuze y Félix Guattari en septiembre de 1972, Foucault mostraba que algunos mecanismos de control que en el siglo XIX practicaba el Estado, a través de los bancos y del ejército, en la actualidad los desarrollaban los privados. Ahora bien, estos mecanismos de control, tendientes a lograr comportamientos normales, eran presentados en términos represivos: "[A]ctualmente se ha privatizado esta forma de represión; se le ha dado la forma de una instancia de control de la normalidad: psicología, policía privada, sindicatos, comités de empresa" (Foucault, 2001a, p. 1324).

Por entonces todavía no se hacía presente la apuesta por despegar la noción de poder de la idea de represión, y esto quizá se explique porque, en esa época, Foucault no se interrogaba cómo funcionaba el poder. Esta ausencia de cuestionamiento puede advertirse en una famosa conversación mantenida con Deleuze en marzo de 1972. Allí afirmaba que, hacia el siglo XIX, Marx había logrado dar cuenta de qué era la explotación, pero todavía estábamos en dificultades para responder a la pregunta: ¿qué es el poder? Ni Marx ni Freud, siempre de acuerdo con Foucault, resultaban demasiado útiles para responder. Del mismo modo, la "teoría del Estado, el análisis tradicional de los aparatos de Estado, sin duda no agotan el campo de ejercicio y de funcionamiento del poder. La gran incógnita actual es: ¿quién ejerce el poder?, ¿dónde lo ejerce?" (Foucault, 2001k, p. 1180). Como vemos, Foucault se preguntaba por el quién y por el lugar del poder, pero no por su modo de ejercicio. Pareciera, pues, que todavía no estaba pensando en los efectos productivos del ejercicio del poder. Más bien, y al contrario, parecía concebir el poder en términos negativos y ni se interrogaba si este diagnóstico era apropiado. Es así que, a renglón seguido de aquellas preguntas, se lee que "habría que saber bien hasta dónde se ejerce el poder, mediante qué relevos y hasta cuáles instancias a menudo ínfimas, de jerarquía, de control, de vigilancia, de prohibiciones, de obligaciones. En todos lados donde hay poder, el poder se ejerce" (Foucault, 2001 k, p. 1181). Es cierto, el poder se ejerce, se ejerce en todo el entramado de la sociedad -reflexiones recurrentes en la obra de Foucault-, pero por ahora pareciera ser que la herramienta de ejercicio es la prohibición o la represión. Incluso, en varios momentos de la conversación, Deleuze se 
refirió al poder en términos de represión, ${ }^{3}$ y esto en ningún momento fue problematizado por Foucault.

En estas primeras referencias, Foucault aludía al poder en términos genéricos, sin acompañamientos de adjetivos. De todos modos, prontamente las aproximaciones conceptuales ya no serán hacia el poder 'a secas', sino hacia el poder disciplinario. Es cuando tematiza sobre el poder disciplinario el momento en el cual Foucault comienza a pensar las relaciones de poder en términos positivos. Es cuando empieza a pensar las relaciones de poder en términos positivos cuando inicia su camino de recluir a la ley a un mero funcionamiento represivo y prohibitivo.

\section{Poder disciplinario y poder productivo}

No contando con la publicación de Teoría e instituciones penales ni de $\mathrm{La}$ sociedad punitiva, los primeros desarrollos sobre el poder disciplinario los encontramos en La verdad y las formas jurídicas - una serie de cinco conferencias dictadas por Foucault en mayo de 1973 en Río de Janeiro- y en "El poder psiquiátrico" -curso dictado entre el 7 de noviembre de 1973 y el 6 de febrero de 1974-. Allí ya aparecen los elementos centrales del poder disciplinario, de un tipo de ejercicio de poder que opera en espacios de encierro y que, a partir de un dispositivo de visibilidad, permite realizar un control sobre los movimientos del cuerpo y la utilización del tiempo de los individuos. Ni en la serie de conferencias ni en el curso, Foucault plantea explícitamente la necesidad de pensar las relaciones de poder en términos productivos, pero sí hay reflexiones que luego decantarán en ese postulado.

En el caso de La verdad y las formas jurídicas, no sostiene explícitamente que las relaciones de poder producen saberes, pero esto se encuentra muy presente a lo largo de las cinco conferencias. Es así que en la primera se proponía "mostrar cómo las prácticas sociales pueden llegar a engendrar dominios de saber que no solamente hacen aparecer nuevos objetos, nuevos 
conceptos, nuevas técnicas, sino también hacen nacer formas totalmente nuevas de sujetos y de sujetos de conocimiento" (Foucault, 2001 h, p. 1406). En particular, le interesaba "[...] mostrar cómo se ha podido formar, en el siglo XIX, un determinado saber del hombre, de la individualidad, del individuo normal o anormal, dentro o fuera de la regla, un saber que, en verdad, ha nacido de las prácticas de control y de vigilancia" (Foucault, 2001h, p. 1407).

Luego de describir las instituciones de secuestro -escuelas, cárceles, hospitales y fábricas-, y el modo en que en ellas se activan procesos de vigilancia tendientes a adiestrar las fuerzas de los hombres y a transformar su tiempo en tiempo útil, Foucault sugirió que, en el marco de estas prácticas de vigilancia, emergió un determinado tipo de saber. En estas instituciones de vigilancia, se extraía un saber que los mismos individuos producían, por ejemplo, al manipular las máquinas o al realizar sus prácticas cotidianas, pero también allí nació "un saber de observación, un saber de algún modo clínico, como el de la psiquiatría, de la psicología, de la psicosociología, de la criminología" (Foucault, 2001h, p. 1488). De este modo, el poder disciplinario "ha provocado el nacimiento de una serie de saberes -saber del individuo, de la normalización, saber correctivo- que se multiplicaron en esas instituciones de subpoder, haciendo aparecer las susodichas 'ciencias del hombre' y el hombre como objeto de la ciencia" (Foucault, 2001h, p. 1490).

Por su lado, en el curso titulado "El poder psiquiátrico", la temática analizada fue la disciplinarización de la locura y el modo en que el asilo psiquiátrico, tal como se instituyó en el siglo XIX, se erigió en un mecanismo disciplinario y, por ello, terapéutico (Gros, 1996, pp. 71-72). Más allá de los lineamientos generales del curso, Foucault insistió en que el poder no se concentraba en el Estado y apostaba por analizar las relaciones de poder en tanto productoras de regímenes discursivos. Al igual que lo que sucedía con La verdad y las formas jurídicas, Foucault no conceptualiza al poder en términos productivos, pero, incluso sin hacerlo, parece indicar que uno de sus efectos, uno de los elementos que produce es un tipo especial de subjetividad: un cuerpo dócil.

Foucault narra la escena que suele presentarse como fundadora de la psiquiatría moderna, en la cual en el Hospital de Bicêtre, Philippe Pinel ordenó que se quitaran las cadenas a los locos, y estos, en lugar de hacer 
estallar su furia, le expresaron su reconocimiento e ingresaron en la senda del proceso de curación. Sin embargo, se sumerge en el análisis de otro relato, incluido por Pinel en su Tratado médico-filosófico y que refiere a la destitución -que no fue definitiva- en 1788 de Jorge III, rey de Gran Bretaña e Irlanda, quien había enloquecido. En este caso, hay una ceremonia de destitución del rey, pero su lugar no es ocupado por otro monarca, sino que hay un tránsito hacia otra tecnología de poder: el poder disciplinario. Es así que en lugar de

[...] ese poder decapitado y descoronado se instala un poder anónimo, múltiple, pálido, sin color, que es en el fondo el poder que llamaré de la disciplina. Un poder del tipo de la soberanía es remplazado por un poder que se podría calificar de disciplina, y cuyo efecto no es en absoluto consagrar el poder de alguien, concentrar el poder en un individuo visible y con nombre, sino de producir efecto sobre su blanco, sobre el cuerpo y la persona misma del rey descoronado, que debe ser tornado 'dócil y sumiso' por este nuevo poder (Foucault, 2003, p. 23).

Más allá de estos indicios que pueden leerse en La verdad y las formas jurídicas, y en "El poder psiquiátrico", en donde ya se vislumbra que el poder produce saberes y subjetividades, fue en el curso dedicado a "Los anormales", dictado entre el 8 de enero y el 19 de marzo de 1975, y en Vigilary castigar, publicado en febrero de 1975 -en medio del dictado del curso-, donde Foucault insistió por primera vez sobre la necesidad de pensar las relaciones de poder en términos no represivos, sino productivos.

En 1975, en el curso sobre "Los anormales", Foucault apostaba a mostrar el modo en que el denominado poder normalizador había emergido por fuera de las instituciones jurídicas y médicas, a la vez que creaba un dominio específico de intervención que no eran los enfermos ni los delincuentes, sino los anormales. De la confluencia del monstruo, el onanista y el incorregible, emergió la figura del anormal y, al afirmarse como ciencia de la anormalidad peligrosa, la psiquiatría se constituyó como un instrumento de higiene social (Gros, 1996, p. 72).

La primera clase se inició con la lectura de dos pericias judiciales, la primera de 1955 y otra de 1975, y Foucault enfatizaba en que el poder normalizador había emergido por fuera del discurso médico y judicial, por 
lo que planteaba, a modo de hipótesis, que "estas técnicas de normalización, y los poderes de normalización ligados a ellas, no son simplemente el efecto del encuentro, de la composición, del empalme el uno sobre el otro del saber médico y el poder judicial, sino que, de hecho, a través de toda la sociedad moderna, es un cierto tipo de poder -ni médico ni judicial, sino otro- que ha logrado colonizar y reprimir el saber médico y el poder judicial" (Foucault, 2001j, p. 24). Foucault destacó que sobre el poder de normalización ya existían algunos trabajos, pero basados en una idea de poder como represión.

"Es decir que esos análisis implican la referencia a un poder cuya principal función sería la represión, cuyo nivel de eficacia sería esencialmente superestructural, del orden de la superestructura, y cuyos mecanismos, por último, estarían esencialmente ligados al desconocimiento, al enceguecimiento" (Foucault, 2001j, p. 40).

He aquí, pues, la apuesta foucaultiana a desprenderse de la idea de poder como represión, cuyo paradigma se encuentra en el tratamiento de la lepra durante el Medioevo.

Durante la Edad Media, la exclusión de los leprosos implicaba la partición rigurosa entre grupos de individuos, la expulsión de los leprosos más allá de las murallas de la ciudad y la descalificación jurídica y política de los leprosos expulsados.

En resumen, eran, en efecto, prácticas de exclusión, prácticas de rechazo, de 'marginación', como diríamos hoy [...]. Se describe, en general los efectos y los mecanismos de poder que se ejercen sobre ellos como mecanismos y efectos de exclusión, de descalificación, de exilio, de rechazo, de privación, negación, desconocimiento, es decir, todo el arsenal de conceptos o mecanismos negativos de la exclusión (Foucault, 2001 j, p. 40).

Este modelo de la exclusión se reactivó a mediados del siglo XVII con la captura de mendigos, vagabundos, ociosos, libertinos, etc., pero ha dejado de funcionar hacia fines del siglo XVII y principios del XVIII, y su lugar fue ocupado por el modelo de la peste. Ante una peste, la ciudad se dividía en distritos y estos en barrios, se instauraba la presencia de un vigilante en cada calle, quienes reportaban sobre la situación a los inspectores de barrios y estos a los responsables del distrito y, a su vez, había un gobernador 
nombrado por cada ciudad. De algún modo, lo que se articulaba era un poder continuo: a) por un lado, porque no se producía ninguna interrupción desde el centinela que vigilaba la puerta de cada una de las casas hasta los responsables de la ciudad; b) por otro lado, porque se trataba de un poder continuo en su ejercicio, ya que la vigilancia debía ejercerse sin ningún tipo de interrupción. Al comienzo de la cuarentena, los ciudadanos tenían la obligación de ser registrados, luego los inspectores pasaban dos veces por día por las puertas de las casas y llamaban por los nombres y, si no se asomaban por la ventana, se los tenían por enfermos y se confeccionaba una grilla de clasificación entre enfermos y no enfermos.

Foucault narra la existencia de un sueño literario de la peste, pero enfatiza en un sueño político de la peste, que representa

[...] el momento maravilloso en que el poder político se ejerce a pleno. La peste es el momento en que el cuadriculado de una población se realiza a su punto extremo, donde ya ninguna de las comunicaciones peligrosas, las comunidades confusas, los contactos prohibidos puede producirse. El momento de la peste es el del cuadriculado exhaustivo de una población por un poder político, cuyas ramificaciones capilares llegan sin parar hasta el grano de los individuos mismos, sus tiempos, su hábitat, su localización, su cuerpo (Foucault, 2001j, p. 44).

El reemplazo del modelo de la lepra por el de la peste se sitúa en el marco de la

[...] invención de las tecnologías positivas del poder. La reacción a la lepra es una reacción negativa; una reacción de rechazo, exclusión, etc. La reacción a la peste es una reacción positiva; una reacción de inclusión, de observación, de formación de saber, multiplicación de los efectos de poder a partir de acumulación de la observación y el saber. Se ha pasado de una tecnología de poder que persigue, que excluye, que destierra, que margina y que reprime, a un poder que es finalmente un poder positivo, un poder que fabrica, un poder que observa, un poder que sabe y un poder que se multiplica a partir de sus propios efectos (Foucault, 2001 j, p. 44).

La instauración en el siglo XVIII de un sistema disciplinario con efectos de normalización implicó la puesta en funcionamiento de poder que, de 
hecho, no es represivo sino productivo -la represión no figura en él, más que a título de efecto lateral y secundario, con respecto a mecanismos que son centrales en relación con ese poder, mecanismos que fabrican, mecanismos que crean, mecanismos que producen

[...] un poder que no es de superestructura, sino que está integrado al juego, a la distribución, a la dinámica, a la estrategia, a la eficacia de las fuerzas; un poder, pues, invertido directamente en el reparto y el juego de las fuerzas [...] un poder que no es conservador, sino un poder que es inventivo, un poder que posee en sí mismo los principios de transformación e innovación [...] un tipo de poder que no está ligado al desconocimiento sino que, al contrario, solo puede funcionar gracias a la formación de un saber, que es para él tanto un efecto como una condición de su ejercicio(Foucault, 2001 j, p. 48).

En "Los anormales", se advierte una notable insistencia por pensar al poder disciplinario no en términos represivos, negativos y prohibitivos, sino productivos, algo que también está muy presente en Vigilar y castigar. El nacimiento de la prisión. Allí proponía ubicar el sistema punitivo desarrollado durante el último siglo y medio dentro de una economía política del cuerpo, siendo que el cuerpo quedaba situado dentro de un campo político que lo hacía, a la vez, cuerpo productivo y cuerpo sometido. Ahora bien, ese sometimiento no debía ubicarse en el nivel de la ideología, ni en el de la violencia, sino en el de una microfísica del poder, admitiendo que el poder

[...] se ejerce más que se posee, que no es el 'privilegio' adquirido o conservado de la clase dominante, sino el efecto conjunto de sus posiciones estratégicas -efecto que manifiesta y a veces acompaña la posición de aquellos que son dominados-. Ese poder, por otra parte, no se aplica pura y simplemente como una obligación o como una prohibición, a aquellos que 'no lo tienen'; él los inviste, pasa por ellos y a través de ellos; él se apoya en ellos, así como ellos mismos, en su lucha contra él, se apoyan a su vez sobre las aprehensiones que él ejerce sobre ellos (Foucault, 1975, pp. 31-32).

Es así que, dentro de las reglas por seguir para llevar a cabo el análisis, entendía que era necesario "[n]o centrar el estudio de los mecanismos 
punitivos sobre sus únicos efectos 'represivos', en su único aspecto de la 'sanción', sino colocarlos en toda una serie de efectos positivos que pueden inducir, aun cuando sean marginales a primera vista" (Foucault, 1975, p. 28). Tal como se advierte en las primeras páginas del libro, Foucault presenta un fuerte ataque a la idea de poder como represión.

Ahora bien, lo curioso es que, en los trabajos en los cuales Foucault explícitamente rechazó una concepción represiva de las relaciones de poder y, con una notable frescura teórica, apostó por pensar las relaciones de poder en términos productivos, implícitamente mantuvo al derecho funcionando de modo exclusivamente represivo, negativo.

Si bien los trabajos en los cuales se analiza la vinculación entre el derecho y el poder disciplinario en la obra de Foucault no son muy numerosos, algunos autores han marcado y criticado el modo en que la ley es reducida a un simple mecanismo de prohibición -y por ello relegada a un segundo plano en un diagrama de poder que funciona preponderantemente de modo positivo y productivo-.

Alan Hunt y Gary Wickham (1994, p. 40) postulan que sistemáticamente Foucault "vincula la ley con la concepción negativa del poder de la cual se esfuerza por escapar", y no hace más que adoptar acríticamente la fórmula positivista según la cual la ley sería solamente una regla acompañada de una sanción, pero no logra constituir una mirada más sofisticada del funcionamiento del derecho (Hunt y Wickham, 1994, p. 41). En este mismo orden de ideas, Duncan Kennedy, leyendo la clase del 14 de enero de 1976, advierte que Foucault presenta una "discontinuidad radical entre el poder legal y el poder disciplinario" (Kennedy, 1991, p. 356). Así mismo, Paul Hirst postula que Foucault tiende a "contraponer la regulación legal y la regulación disciplinaria" (Hirst, 1986, p. 50), y en sus trabajos "la ley es marginada, las intervenciones legales devienen secundarias respecto a una masa de intervenciones normalizadoras" (Hirst, 1986, p. 40). ${ }^{4}$ Del mismo modo, para Boaventura de Sousa Santos, "Foucault exagera una mutua incompatibilidad entre el poder jurídico y el poder disciplinario, y pasa por alto las profundas interpenetraciones entre ambos" (De Sousa Santos, 2002 , p. 5) y plantea que estas dos formas de poder "son incompatibles, y el poder científico y normalizador de las disciplinas se ha transformado

4 En similar sentido, Hirst (1980, p. 92). 
en la forma de poder más penetrante en nuestra sociedad" (De Sousa Santos, 2002, p. 6). ${ }^{5}$

Aquí, al menos en parte, sigo la línea de los autores mencionados, pero creo que me distancio de ellos en dos puntos. El primero, el menos relevante, es que, mientras los trabajos anteriores suelen abordar Vigilar y castigar, La voluntad de saber y las primeras dos clases de "Hay que defender la sociedad", yo agrego un análisis del curso dedicado a "Los anormales". Además, y creo que este punto es más interesante, si bien los autores mencionados critican esta reducción de la ley a una mera herramienta de represión y prohibición, mi trabajo muestra que esto es problemático incluso tomando los mismos ejemplos históricos, y hasta los mismos materiales de archivo analizados por Foucault. De algún modo, mi crítica no será tanto externa a las investigaciones de Foucault, sino que intento realizarla partiendo de sus propios términos.

\section{Poder productivo y derecho negativo}

En el curso sobre "Los anormales", es bien extensa la necesidad de desprenderse de una concepción de poder ligada a una idea de represión. Muy por el contrario, es muy breve la referencia al derecho, aunque estos pequeños pasajes reducen la ley a mera represión y prohibición. Para dar cuenta del modo en que Foucault reduce la ley a un mero dispositivo de prohibición, es menester analizar el tratamiento que realiza sobre el individuo por corregir. Nuestro autor afirma que el anormal del siglo XIX es descendiente del monstruo, el onanista y el individuo por corregir (Foucault, 2001 j, pp. 51-55). Si bien hay extensos desarrollos sobre el monstruo y el onanista, en las dos últimas clases del curso -12 y 19 de marzo de 1975-, Foucault insistió en que no había tenido el tiempo suficiente para avocarse al tratamiento del indisciplinado o niño indócil, aunque también aclaró que su análisis no era indispensable (Foucault, 2001 j, pp. 258-259, 269). No obstante, y curiosamente, en el resumen del curso sí aparece una referencia al indisciplinado.

El individuo por corregir es una figura más tardía que la del monstruo y, a diferencia de este, no se presentaba como el correlato de la ley. Más bien,

5 En el mismo sentido, p. 356. 
[1]a aparición del incorregible es contemporánea a la puesta en práctica de las técnicas de disciplina, a la que se asiste durante el siglo XVII y XVIII -en el ejército, en las escuelas, en los talleres y, un poco más tarde, en las familias mismas-. Los nuevos procedimientos de encauzamiento del cuerpo, del comportamiento y de las aptitudes, inauguran el problema de quienes escapan a esta normatividad que ya no es la soberanía de la ley (Foucault, 2001j, p. 1692).

Los incorregibles eran aquellos que escapaban a una normatividad que no es una normatividad de la ley y es aquí cuando Foucault asocia a la normatividad que propone la ley a una mera prohibición. Así se lee que "[l]a 'prohibición' constituía la medida judicial mediante la cual un individuo era, al menos parcialmente, descalificado como sujeto de derecho" (Foucault, 2001 j, p. 1692). En la misma línea, asociando el marco jurídico a un dispositivo meramente negativo, agregó que

[e]se marco, jurídico y negativo, va a ser en parte ocupado y en parte reemplazado por un conjunto de técnicas y procedimientos con los que se emprenderá encauzar a aquellos que se resisten al encauzamiento y corregir a los incorregibles. El 'encierro' practicado en gran escala a partir del siglo XVII puede aparecer como una especie de fórmula intermedia entre el procedimiento negativo de la prohibición judicial y los métodos positivos de enderezamiento (Foucault, 2001 j, pp. 1692-1693).

Según entiendo, aquí hay dos elementos importantes que se deben tener en cuenta: a) la reducción del derecho a mera prohibición, una mirada que tal vez tenga cierto sustento porque parecería que las referencias son hacia el derecho penal; b) el diagnóstico según el cual el marco jurídico y negativo fue desplazado por las tecnologías disciplinarias. Esta mirada represiva sobre el derecho, y este desplazamiento del derecho por las técnicas disciplinarias, también se advierte en Vigilar y castigar.

A lo largo de toda la indagación sobre el Nacimiento de la prisión, puede advertirse una estrecha asociación entre ley y represión, ley y castigo, ley y penalidad, algo que es sumamente entendible porque durante gran parte del trabajo encontraba analizando, mayormente, cuerpos legales propios del derecho penal. Por su lado, en el capítulo dedicado a los medios del buen encauzamiento, Foucault muestra que el éxito del poder disciplinario radica 
en el empleo de instrumentos muy simples, como la vigilancia jerárquica, la sanción normalizadora y el examen. Respecto de la sanción normalizadora, y a modo de resumen del desarrollo que se realiza sobre la temática, se lee que "[...] el arte de castigar, en el régimen del poder disciplinario, no tiende ni a la expiación ni tampoco exactamente a la represión. Él pone en funcionamiento cinco operaciones bien distintas: referir los actos, los rendimientos, las conductas singulares a un conjunto que es a la vez campo de comparación, espacio de diferenciación y principio de una regla que seguir" (Foucault, 1975, p. 185).

Es así que

[...] el régimen del poder disciplinario se opone pues término a término una penalidad judicial que tiene por función esencial referirse, no a un conjunto de fenómenos observables, sino a un corpus de leyes y de textos que hay que guardar en la memoria; no de diferenciar individuos, sino de especificar los actos bajo un determinado número de categorías generales; no de jerarquizar sino de hacer jugar pura y simplemente la oposición binaria de permitido y prohibido; no de homogeneizar, sino de operar la división, obtenida de una vez por todas, de la condena. Los dispositivos disciplinarios han secretado una 'penalidad de la norma', que es irreductible a los principios y su funcionamiento a la penalidad tradicional de la ley (Foucault, 1975, p. 185).

En este caso, puede advertirse que Foucault mantiene una idea del orden de lo legal atravesado por la dicotomía de lo permitido y lo prohibido, mientras las sanciones disciplinarias no se hallan en ese registro dicotómico, que queda reservado para las sanciones legales.

Según entiendo, de esta oposición, parece surgir que lo legal queda necesariamente limitado a un mero juego de lo prohibido y lo permitido, puesto que la penalidad de la ley pareciera ser impermeable por la penalidad de la norma. Por algún motivo, por alguna circunstancia que a primera vista no es posible explicar, el funcionamiento general del poder disciplinario no ha logrado capturar el funcionamiento de la ley e impregnarle su accionar productivo. De algún modo, cuando en "Los anormales" había analizado superficialmente al niño indócil, Foucault ya había separado los dominios del poder legal y del poder de normalización. Esta separación se reitera en Vigilar y castigar, no solamente al momento de tematizar sobre la 'sanción 
normalizadora', sino también en términos más genéricos. En el primer capítulo, a modo de premisa metodológica, Foucault indicaba que era necesario "[a]nalizar los métodos punitivos no como simples consecuencias de reglas de derecho o como indicadores de estructuras sociales; sino como técnicas que tienen su especificidad dentro del campo más general de otros procedimientos de poder" (Foucault, 1975, p. 28).

En la misma línea que lo anterior, en el capítulo dedicado al panoptismo, sostenía que la modalidad panóptica del poder no se había desarrollado ni había implicado la prolongación de las instituciones jurídico-políticas, aunque tampoco se había desarrollado de modo completamente independiente. En el siglo XVIII, la burguesía ha instalado un marco jurídico codificado, explícito, formalmente igualitario y un sistema de gobierno representativo y parlamentario.

"Pero el desarrollo y la generalización de los dispositivos disciplinarios ha constituido la otra vertiente, oscura, de esos procesos. La forma jurídica general que garantizaba un sistema de derechos en principio igualitarios estaba sostenida por esos mecanismos menudos, cotidianos, y psíquicos, por todos esos sistemas de micro-poder esencialmente desigualitarios y disimétricos que constituyen las disciplinas" (Foucault, 1975, p. 223).

Quizás en apariencia las disciplinas se erigen como un infraderecho, prologando a nivel particular, específico, las formas generales definidas por las instituciones del derecho. De algún modo, parecerían constituir el mismo derecho, pero a una escala menor, considerablemente más precisa. No obstante, "más bien hay que ver en las disciplinas una especie de contraderecho. Ellas tienen el rol preciso de introducir una disimetrías insuperables y de excluir las reciprocidades" (Foucault, 1975, p. 223). De este modo,

[...] mientras que los sistemas jurídicos clasifican los sujetos de derecho, según normas universales, las disciplinas caracterizan, clasifican, especializan; ellas distribuyen a lo largo de una escala, reparten alrededor de una norma, jerarquizan los individuos los unos en relación con los otros, y en el límite descalifican e invalidan. De todas formas, en el espacio y durante el tiempo en que ellas ejercen su control y hacen actuar las disimetrías de su poder, ellas efectúan una puesta en suspenso, jamás total, pero tampoco anulada, del derecho. Por tan regular e institucionalizada que sea, la disciplina, en su mecanismo, es un 'contra-derecho'. Y si 
el juridicismo universal de la sociedad moderna parece fijar los límites al ejercicio de los poderes, su panoptismo por todos lados expandido hace funcionar, en sentido contrario del derecho, una maquinaria a la vez inmensa y minúscula que sostiene, refuerza, multiplica la disimetría de los poderes y, vuelve vanos los límites que se le han trazado [...]. Ellas han sido, en la genealogía de la sociedad modenra, con la dominación de clase que la atraviesa, la contrapartida política de las normas jurídicas según las cuales se redistribuía el poder (Foucault, 1975, p. 224). ${ }^{6}$

Por su lado, en Historia de la sexualidad I. La voluntad de saber, insistió notablemente sobre esta dimensión negativa de la ley. La apuesta de ese primer volumen, y la de los libros subsiguientes, era "avanzar menos hacia una 'teoría' que hacia una 'analítica' del poder: quiero decir, hacia la definición del dominio específico que forman las relaciones de poder y la determinación de los instrumentos que permiten analizarlo" (Foucault, 1976, p. 109). Esta nueva analítica de las relaciones de poder solo podía constituirse dejando de lado la representación jurídica del poder, cuyos caracteres centrales eran: a) la relación negativa. Este tipo de representación propone que "[e]ntre el poder y el sexo, sólo se establece una relación de modo negativo: desestimación, exclusión, rechazo, barrera, o incluso ocultación o máscara. El poder nada puede sobre el sexo, salvo decirle no" (Foucault, 1976, p. 109); b) la instancia de la regla, según la cual "[ell poder sería eso que, al sexo, dicta su ley. Quiero decir, ahora, que el sexo se encuentra colocado por él bajo un régimen binario: lícito e ilícito, permitido y prohibido" (Foucault, 1976, p. 110); c) el ciclo de lo prohibido, que estipula que no tocarás, que no consumirás ni sentirás placer, que no hablarás del sexo, y que este solamente existirá en las sombras o en el ámbito de lo secreto. "Sobre el sexo el poder sólo aplicaría una ley de prohibición. Su objetivo: que el sexo renuncie a sí mismo. Su instrumento: la amenaza de un castigo que no es otro que su supresión" (Foucault, 1976, pp. 110-111);

6 En esta línea, distinguiendo ambas esferas, pero un año antes, en una conferencia titulada "¿Crisis de la medicina o crisis de la antimedicina?", pronunciada en el Instituto de Medicina Social de la Universidad del Estado de Río de Janeiro, Foucault ya había adelantado la hipótesis según la cual, "Isli los juristas de los siglos XVII y XVIII inventaron un sistema social que debía estar dirigido por un sistema de leyes codificadas, se puede afirmar que los médicos del siglo XX están en camino de inventar una sociedad de la norma y no de la ley. Lo que rige la sociedad no son los códigos sino la distinción permanente entre lo normal y lo anormal, la empresa perpetua de restituir el sistema de la normalidad" (Foucault, 2001b, p. 50). 
d) la lógica de la censura, según la cual la prohibición mencionada puede adoptar tres modalidades: "Afirmar que eso no está permitido, impedir que eso sea dicho, negar que eso exista" (Foucault, 1976, p. 111); e) la unidad del dispositivo, según la cual el poder se ejercería del mismo modo en todos los niveles, tanto en decisiones globales cuanto en sus intervenciones capilares. En todos los aparatos o instituciones, actuaría de manera uniforme. Aunque a diferente escala, en todos estos ámbitos, existiría una forma similar del poder: "Esta forma es el derecho, con el juego de lo lícito y lo ilícito, de la transgresión y del castigo [...]. Frente a un poder que es ley, el sujeto está constituido como sujeto -que está 'sujeto' - es el que obedece" (Foucault, 1976, pp. 111-112).

Según entiendo, cuando Foucault sostiene que el poder sería aquello que al sexo dicta su ley, pero, al momento de caracterizar esta ley, sus caracteres están reducidos a: lícito/ilícito y prohibido/permitido. Del mismo modo, en su referencia a la unidad del dispositivo, la forma del derecho, que es la que dotaría esta unidad, queda reducida nuevamente Foucault a los pares dicotómicos: lícito/ilícito y transgresión/castigo. Los mismos problemas se presentan cuando Foucault resume todas sus críticas hacia la representación jurídica del poder y sostiene que, si nos aferramos a ella, estaremos ante una mirada demasiado pobre sobre el poder: a) en primer lugar, porque se trataría de un funcionamiento del poder demasiado limitado en sus recursos y estrategias y muy monótono en las tácticas que utiliza; b) en segundo lugar, porque se trataría de un funcionamiento que únicamente estaría en condiciones de impedir y ello lo transformaría en incapaz de producir comportamientos; c) por último, y aquí aparece nuevamente su reducción de la ley a una mera prohibición, "porque es un poder cuyo modelo sería esencialmente jurídico, centrado en el solo enunciado de la ley y el solo funcionamiento de lo prohibido" (Foucault, 1976, p. 113).

Tal como Foucault presenta las cosas, la norma y la ley parecen ser cosas bien distintas, y todo indicaría que la norma no puede funcionar a partir de la ley, ni la ley puede funcionar como norma. Ahora bien, lo curioso es que, para Foucault, "[l]a disciplina no puede identificarse ni con una institución ni con un aparato; ella es un tipo de poder, una modalidad para ejercerlo, que comporta todo un conjunto de instrumentos, de técnicas, de procedimientos, de niveles de aplicación, de blancos; ellas es una 'física', o una 'anatomía' del poder, una tecnología" (Foucault, 1975, p. 217). 
La disciplina puede ser incluida en instituciones específicas, como las penitenciarías o las casas de corrección; en instituciones que la emplean para logar un fin determinado, como hospitales o escuelas; puede ser utilizada en diversas instancias para reforzar o reorganizar mecanismos ya existentes -así sucede, por ejemplo, en el caso de las familias durante la edad clásica-; puede ser asumida por aparatos estatales cuyo principio sea la disciplina -como es el caso de la burocracia napoleónica- o por aparatos -como la policíacuya función exclusiva no sea la disciplina (Foucault, 1975, pp. 217-218). Ahora bien, vinculando este diagnóstico con la temática del derecho, creo que estamos ante dos posibilidades: a) la disciplina impregnó todas las instituciones, excepto la institución judicial; b) la disciplina impregnó la institución judicial, pero no ha perforado la ley, que sigue funcionando de modo prohibitivo. No obstante, creo que estamos ante dos opciones que, en definitiva, reducen la ley, a pesar del avance de este dispositivo disciplinario que implica un poder productivo, a un rol meramente negativo. Esto resulta por demás curioso puesto que el propio Foucault ha sostenido que en determinado contexto histórico las disciplinas también habían cumplido una función eminentemente represiva y prohibitiva, pero, hacia el siglo XVIII, se produjo una inversión funcional de las disciplinas, y comenzaron a actuar en términos eminentemente productivos. Sin embargo, y por motivos que no resultan muy claros, parece ser que esta inversión no se ha producido en el ámbito de la ley.

De los desarrollos que presenta Foucault, pareciera que la ley no puede funcionar en términos productivos, que la ley no puede ser el vehículo para la instauración de los mecanismos disciplinarios. Esto no solamente que no parece lo suficientemente profundizado y explicado a lo largo de su obra, sino que, si se adoptan los ejemplos históricos de instituciones disciplinarias que él mismo ha brindado, la ley parece haber cumplido un papel constitutivo.

\section{La ley disciplinaria}

Quizás el ejemplo más fácil para mostrar el papel que cumple la ley en los dispositivos disciplinarios sea el de la cárcel. Para el caso argentino, sería muy fácil mostrar el modo en que la Ley Nacional de Ejecución Penal (Ley 
24660, sancionada el 19 de junio de 1996 y promulgada el 8 de julio de aquel año) pone en funcionamiento gran parte de los mecanismos disciplinarios descriptos por Foucault. Así mismo, es menester recordar que la prisión como castigo, como castigo exclusivo y generalizado, se ha dispuesto a través de la ley -en Francia, los códigos penales de 1808 y 1810-. En el mismo orden de ideas, es de destacar que el proyecto del Panopticon era algo muy parecido a un proyecto de ley. El Panopticon fue publicado en 1787, $\mathrm{y}$, tal como lo narra el propio Bentham en el prefacio de la publicación, se trata de una serie de 31 cartas escritas en Rusia y enviadas a Inglaterra (Bentham, 1995, p. 31). Ahora bien, junto con los Principios de legislación civil y penal de 1802, el jurista francés Pierre Étienne Louis Dumont, encargado de la publicación de los Principios, incluyó un opúsculo titulado Panopticon, que, como indica Emmanuelle de Champs, es una versión francesa y resumida de Panopticon, or the inspection-house, que había sido publicada en inglés en 1791 (De Champs, s. f.). Esa versión resumida había sido enviada por Bentham a Jean Philippe Garran de Coulon, quien era miembro de la Asamblea Legislativa francesa e integrante de una comisión formada para avanzar hacia una reforma de las leyes penales. Tal como puede advertirse, entonces, el proyecto del Panopticon, símbolo más notable del funcionamiento disciplinario de las relaciones de poder, era un material, un insumo para una reforma legislativa, para reformas sociales llevadas a cabo a partir del instrumento de la ley. Si bien entiendo que, con el ejemplo de la instauración de la cárcel como forma generalizada de castigo, ya resulta inexplicable tanto la separación que Foucault realiza entre la ley y los sistemas disciplinarios, cuanto la reducción de la ley a mera prohibición o represión, entiendo que hay ejemplos más sutiles que también tornan carente de sustento su diagnóstico sobre la ley.

En "El poder psiquiátrico", curso en el cual Foucault brindó algunos de los caracteres del poder disciplinario, se muestra que la generalización de las prácticas disciplinarias tuvo como protagonista a instituciones religiosas. De todos modos, también se exponen algunos ejemplos de instauración de prácticas disciplinarias por fuera de ellas, sin sustento religioso, y una de las maneras de disciplinar a los trabajadores industriales fue la instauración de la cartilla, en la cual se consignaba quiénes habían sido los antiguos empleadores, las razones de abandono de anteriores trabajos, entre otros (Foucault, 2003, pp. 72-73). Ahora bien, tanto durante el siglo XVIII como durante 
el siglo XIX en Francia, la regulación de la cartilla obrera fue instaurada por numerosas disposiciones legislativas. Las primeras reglamentaciones datan de las lettres patentes ${ }^{7}$ dictadas el 2 de enero de 1749, luego se profundiza esta regulación en el artículo 40 del Edicto de Turgot de abril de 1776 y, años más tarde, por las lettres patentes del 12 de septiembre de 1781. Finalmente, el artículo 12 de la ley sobre 'policía del trabajo', sancionada el 12 de abril de 1803, también incluyó una regulación de la cartilla obrera, reglamentaciones que también aparecen en la ley del 18 de marzo de 1806 y en el decreto del 11 de junio de 1809. En todos los casos, en mayor o en menor medida, se obligaba a los empleadores a requerir la cartilla antes de contratar un obrero (Le Crom, 2003, pp. 91-93). De todos modos, no eran únicamente las normas laborales las que obligaban a la utilización de las cartillas. Es así que el artículo 217 del Código Penal disponía que, si un obrero era encontrado por la gendarmería o la policía sin su cartilla, era considerado un vagabundo, podía ser arrestado y la pena prevista era la prisión de uno a tres meses (Le Crom, 2003, pp. 91-93).

Por su lado, si analizamos el ordenamiento de la ciudad ante un caso de peste, paradigma del funcionamiento del poder disciplinario, cuando se consulta el mismo libro que utiliza Foucault en "Los anormales", debe decirse que, además de algunos casos remotos de Grecia, Roma, Etiopía, Egipto y Asia menor, se reseñan declaraciones de peste en ciudades europeas desde los siglos XV y XVI, esto es, algunos siglos antes de la ubicación temporal que describe Foucault. ${ }^{8} \mathrm{El}$ trabajo de Ozanam resume varias obras en las cuales se relata la existencia de peste en numerosas ciudades europeas, principalmente entre los siglos XVI y XVIII. Se muestran los diferentes síntomas -algunos compartidos con otras enfermedades, otros propios de la peste y algunos considerados anómalos-, los relatos de autopsias, la terapéutica utilizada y algunas medidas de prevención. Aquello que Foucault describe, sin la mejor precisión, refiere a las medidas de política sanitaria adoptadas en la Ciudad de Nola -Reino de Nápoles- en diciembre de 1815. Al menos de lo que se desprende del libro de Ozanam, no

7 Las lettres patentes eran actos legislativos dictados por el rey o por algún secretario de Estado, similares a lo que hoy sería un decreto del Consejo de Estado.

8 De este modo, Ozanam refiere a casos de peste en Europa en 1450 y a una declaración de peste en Italia en 1525 (Ozanam, 1835, pp. 11-12). 
es que esas medidas hayan sido las generalmente adoptadas en casos de peste -tal como parece surgir de la presentación de Foucault-, sino que se trataba de las recomendaciones del autor a partir de aquella experiencia en Nola (Ozanam, 1835, p. 64). Así mismo, es de destacar que, además de las medidas de vigilancia cuadriculada que presenta Foucault, se detallan otro tipo de medidas. En este sentido, aparte de la instauración de un hospital para recibir a los enfermos, la ciudad fue cercada por dos fosas de seis pies de largo y de profundidad, y se contemplaba la pena de muerte para quienes intentaran atravesarlas. Por otra parte, se disponía la presencia de 1.200 hombres armados para impedir el ingreso y la salida de la ciudad (Ozanam, 1835, p. 65). También, se cerraron las iglesias, los cafés y lugares públicos, y se ordenó dar muerte a los animales domésticos, y los habitantes, bajo pena de muerte, debían declarar si poseían lanas, pieles o plumas. Y, de hecho, "[u]n individuo aprehendido en contravención fue juzgado por una comisión militar y ejecutado en la plaza pública" (Ozanam, 1835, pp. 66-67). Esta descripción no solamente pone ciertas dudas sobre la oposición tan tajante que propone Foucault entre el modelo de la peste y el de la lepra, sino que además podría sospecharse que todas estas medidas se disponían por la autoridad política, quizá no bajo la forma de ley, pero sí mediante disposiciones legislativas equivalentes -algún tipo de reglamento, de decreto, etc.-. De todos modos, en el texto de Ozanam, no se hace referencia a quién debía establecer este tipo de medidas, ni tampoco a quién lo había dispuesto en el caso específico de la Ciudad de Nola. Sin embargo, puede decirse que, luego de brindar las recomendaciones de política sanitaria, el político católico recomendaba que "cuando la peste se ha manifestado en una ciudad, el magistrado no debe vacilar en publicar la declaración" (Ozanam, 1835, p. 73). Si bien creo que aquí hay una pista que nos indica quién puede instituir estas medidas, en Vigilary castigar, en donde también se describe el orden de la ciudad ante los casos de peste, Foucault aclara que se trata de una descripción que es tomada de uno de varios reglamentos similares (Foucault, 1975, p. 197 nota).

Finalmente, en Vigilary castigar -y también en "El poder psiquiátrico"-, uno de los ejemplos para mostrar los dispositivos de vigilancia y la nueva utilización del tiempo impuesta por los dispositivos disciplinarios son las modificaciones que sufre la manufactura de los gobelinos a principios del siglo XVIII. En 1667, el edicto que la creaba contemplaba la organización 
de una escuela con las siguientes características: se becaban a 60 niños que eran confiados a un maestro tapicero; se estipulaban seis años de aprendizaje, cuatro de servicio y una prueba de suficiencia, tras lo cual se tenía derecho a abrir un establecimiento. Los caracteres del aprendizaje corporativo presentaban una relación directa entre maestro y aprendiz, proponían una formación sin programas específicos y la finalización del proceso de aprendizaje estaba dada por una prueba calificadora. Ahora bien, Foucault narra que en 1737 un edicto reorganizó la escuela de los gobelinos, implicando, en lo que aquí merece ser destacado, una reorganización en el empleo del tiempo y en las prácticas de enseñanza: a) con excepción de los sábados y domingos, se estipulaban dos horas diarias de presencia en la escuela y se pasaba lista de asistencia; b) la escuela quedaba dividida en tres clases de acuerdo al nivel de conocimiento de dibujo; c) se obligaba a los alumnos la realización de deberes individuales de modo periódico y cada fin de año se medía el grado de progreso. De este modo, "[lla escuela de los gobelinos no es más que un ejemplo de un fenómeno importante: el desarrollo, en la época clásica, de una nueva técnica para tomar a su cargo el tiempo de las existencias singulares; para regir las relaciones del tiempo, de los cuerpos y de las fuerzas; para asegurar una acumulación de la duración; y para invertir en provecho o en utilidad siempre creciente el movimiento del tiempo que pasa" (Foucault, 1975, p. 1599).

Recordemos que la manufactura de los gobelinos, si bien tiene como antecedente los telares creados por Enrique IV en 1607, fue instituida en 1664, en pleno régimen absolutista, por Jean-Baptiste Colbert, ministro de la Corte de Luis XIV, y su nombre oficial era Manufacture Royale des Meubles de la Couronne [Manufactura Real de Muebles de la Corona] y, además de tapices - que en la actualidad continúa confeccionando-, se encargaba de todo lo relativo a la elaboración del amueblamiento de los palacios reales -excepto de las alfombras, que se confeccionaban en las Manufacturas de Savonnerie-. Ahora bien, siendo que se trataba de algo que hoy denominaríamos 'dependencia estatal', sus reglas de organización se estipulaban a través de disposiciones normativas, específicamente de edictos y resoluciones (Arrêt) del Consejo de Estado del Rey. Es más, incluso trabajando con el mismo libro con el que lo hace Foucault, Le Manufacture Nationale des Gobelins de Edóuard Gerspach, se advierte que toda la administración y hasta la creación de la manufactura se realizó por edictos 
reales. Además, es raro que Foucault no haya advertido la importancia de los edictos -siendo que incluso los cita-; el libro de Gerspach se inicia con un párrafo de la exposición de motivos del edicto de noviembre de 1667 firmado por Luis XIV: Edicto del Rey para el establecimiento de una manufactura de muebles en los gobelinos (Gerspach, 1892, p. 1). De todos modos, las disposiciones legales, normativas, no solamente fueron de importancia para la creación de la Manufactura, sino que además la reorganización que se produjo en 1737, y que, para Foucault, se erige como una muestra del nuevo control sobre el tiempo y sobre los cuerpos que imprime el poder disciplinario, fue dispuesta por una Resolución del Consejo de Estado del Rey del 16 de abril de 1737 (Gerspach, 1892, pp. 263 y ss.).

\section{Notas finales}

Sin la pretensión de elaborar una teoría del poder, sino más bien de brindar las premisas metodológicas para dar cuenta de las relaciones de poder, entiendo que las reflexiones desarrolladas por Foucault en el decenio de 1970 aportaron una notable frescura para pensar al poder. Uno de los puntos más notables de estas novedades fue concebir las relaciones de poder en términos productivos más que represivos. Es en este contexto que, según entiendo, resulta por demás problemático recluir el funcionamiento de la ley a una mera prohibición. De hecho, si uno trabaja con algunos de los ejemplos históricos que, para Foucault, dan cuenta de la institucionalización del poder disciplinario, es posible advertir el rol constitutivo de las leyes. Según entiendo, al momento de pensar las relaciones de poder en términos productivos, Foucault ha tenido el problema de seguir concibiendo a la ley como una herramienta que opera exclusivamente a partir de la represión y la prohibición, algo que quizás explica esta dudosa separación entre las leyes y las disciplinas (y las normas).

En el interior de la obra de Foucault, lo que resta analizar es, si esta errónea concepción del funcionamiento de la ley tiene implicancias en otras de las reflexiones que el autor francés ha aportado para pensar las relaciones de poder. Para proponer solamente un ejemplo: ¿puede pensarse que las relaciones de poder son ascendentes si uno logra mostrar que la ley ha tenido un papel constitutivo en las instituciones disciplinarias? Esto merecería 
un trabajo separado, pero, quizá, la errónea conceptualización que Foucault ha tenido respecto de las leyes pueda tener implicancias en otros aspectos de su nueva analítica o nueva economía de las relaciones de poder.

En el exterior de la obra de Foucault, marcar esta inadvertencia del rol constitutivo que tienen las leyes en el funcionamiento de las instituciones disciplinarias, del poder disciplinario, parece abrir un nueva matriz de análisis de las vinculaciones entre el derecho y las relaciones de poder.

\section{Referencias}

Bentham, J. (1995). The Panopticon writings. (M. Božovič, Ed.). London: Verso.

Castro Orellana, R. (2004). Ética para un rostro de arena. Michel Foucault y el cuidado de la libertad (Disertación doctoral no publicada, Universidad Complutense de Madrid, Madrid, España).

De Champs, E. (s. f.). La genèse des traités de législation civile et pénale. Recuperado de http://www.centrebentham.fr/Dumont.html

De Sousa Santos, B. (2002). Toward a new legal common sense. Law, globalization, and emancipation. London: Butterworths-Lexis Nexis.

Foucault, M. (1969). L'archéologie du savoir. Paris: Gallimard.

Foucault, M. (1975). Surveiller et punir. Naissance de la prison. Paris: Gallimard.

Foucault, M. (1976). Histoire de la sexualité I. La volonté de savoir. Paris: Gallimard.

Foucault, M. (2001 a). Arrachés par d'énergiques interventions à notre euphorique séjour dans l'histoire nous mettons laborieusement en chantier des 'catégories logiques'. En Dits et écrits I. Paris: Gallimard.

Foucault, M. (2001b). Crise de la médicine ou crise de l'antimédicine? En Dits et écrits II. Paris: Gallimard.

Foucault, M. (2001 c). De la nature humaine: justice contre pouvoir. En Dits et écrits I. Paris: Gallimard.

Foucault, M. (2001 d). Enquête sur les prisons: brisons les barreaux du silence. En Dits et écrits I. Paris: Gallimard.

Foucault, M. (2001e). Entretien avec Michel Foucault. En Dits et écrits II. Paris: Gallimard.

Foucault, M. (2001f). Je perçois l'intolérable. En Dits et écrits I. Paris: Gallimard.

Foucault, M. (2001 g). La folie, l'absence d'œuvre. En Dits et écrits I. Paris: Gallimard. Foucault, M. (2001h). La vérité et les formes juridiques. En Dits et écrits I. Paris: Gallimard. 
Foucault, M. (2001 i). Le monde est un grand asile. En Dits et écrits I. Paris: Gallimard. Foucault, M. (2001j). Les anormaux. En Dits et écrits I. Paris: Gallimard-Seuil.

Foucault, M. (2001k). Les intellectuels et le pouvoir. En Dits et écrits I. Paris: Gallimard.

Foucault. M. (20011). Par-delà le bien et le mal. En Dits et écrits I. Paris: Gallimard. Foucault, M. (2001 m). Préface. En Dits et écrits I. Paris: Gallimard.

Foucault, M. (2001n). Prisons et révoltes dans les prisons. En Dits et écrits I. Paris: Gallimard.

Foucault, M. (2001 ñ). Réponse à une question. En Dits et écrits. Paris: Gallimard. Foucault, M. (2001 o). Sur la justice populaire. Débat avec les maos. En Dits et écrits I. Paris: Gallimard.

Foucault, M. (2003). Le pouvoir psychiatrique. Cours au Collège de France 1973-1974. Paris: Gallimard-Seuil.

Gerspach, E. (1892). Le Manufacture Nationale des Gobelins. Paris: Librairie Ch. Delagrave.

Godoy, O. (1990). Analítica del poder: en torno a Michel Foucault. Revista Estudios Públicos, (40), 101-135. Recuperado de http://www.cepchile.cl/dms/archivo_1047_1443/rev40_godoy.pdf.

Gros, F. (1996). Michel Foucault. Paris: Presses Universitaires de France.

Hirst, P. Q. (1986). Law, socialism and democracy. Londres: Allen E Unwin.

Hirst, P. Q. (1980). Law, socialism and rights. En P. Carlen E M. Collison (Eds.), Radical issues in criminology. Oxford: Martin Robertson.

Hunt, A., E Wickham, G. (1994). Foucault and law. Towards a sociology of law as governance. London: Pluto.

Kennedy, D. (1991). The stakes of law, or Hale and Foucault! Legal Studies Forum, 25(4), 327-366.

Le Crom, J. P. (2003). Le livret ouvrier au XIXe siècle entre assujettissement et reconnaissance de soi. En D. Gaurier, P. Y. Legal, E Y. Le Gall (Dirs.), Du droit du travail au droits de l'humanité. Études offertes à Philippe-Jean Hesse. Rennes: Presses Universitaires de Rennes.

Ozanam, J. A. (1835). Histoire médicale générale et particulière des maladies épidémiques, contagieuses et épizotiques, qui ont régné en Europe depuis les temps les plus reculés, et notamment depuis le XIVe siècle jus.qu'à nos jours ( $2^{\text {a }}$ ed., vol. IV). Paris: Chez tous libraires pour le médecine. 